\title{
Red cell volume distribution width level predicted postoperative complications and survival in colorectal liver metastases after resection
}

\author{
Huaiyong $\operatorname{Tan}^{1}$, Daxiong Zeng ${ }^{2}$ \\ ${ }^{1}$ Department of Respiratory, Suzhou Guangci Tumor Hospital, Suzhou, China; ${ }^{2}$ Department of Pulmonary and Critical Care Medicine, Suzhou \\ Dushu Lake Hospital Affiliated to Soochow University, Medical Center of Soochow University, Suzhou, China \\ Correspondence to: Dr. Daxiong Zeng. Department of Pulmonary and Critical Care Medicine, Suzhou Dushu Lake Hospital Affiliated to Soochow \\ University, Medical Center of Soochow University, Suzhou 215006, China. Email: zengdaxiong@suda.edu.cn. \\ Comment on: Chen Q, Mao R, Zhao J, et al. Nomograms incorporating preoperative RDW level for the prediction of postoperative complications \\ and survival in colorectal liver metastases after resection. Ann Palliat Med 2021;10:4143-58.
}

Submitted Nov 17, 2021. Accepted for publication Dec 13, 2021.

doi: 10.21037/apm-21-3369

View this article at: https://dx.doi.org/10.21037/apm-21-3369

We recently read the published report by Chen and colleagues with great interest (1). Aiming to examine the prognostic value of preoperative red cell volume distribution width (RDW) level and postoperative complications in patients with colorectal liver metastases (CRLM), this retrospective research enrolled 380 CRLM patients who received treatment of hepatic resection. Their results showed that elevated RDW-CV levels significantly associated with better prognosis, and elevated RDW-SD was evidently associated with poor prognosis. Furthermore, they constructed a nomogram predicting PFS basing on preoperative RDW-CV, RDW-SD, GGT, D-dimer and other clinical markers.

As the authors concluded, this study firstly demonstrated the association of preoperative RDW-SD and preoperative RDW-CV with the prognosis of CRLM patients. Meanwhile, they used nomograms of preoperative blood makers for prediction of postoperative complications, OS as well as PFS. This might benefit for physicians to perform a more suitable clinical management approach for CRLM patients. However, there are some confounding factors should be noticed.

Firstly, plenty of baseline disorders might affect RDW levels (2-6). As a clinical biomarker of red blood cell heterogeneity, RDW is extensively applied as a parameter for the differential diagnosis of anemia. Numerous recent studies showed its crucial clinical value as a predictor in cardiovascular events and prognosis for multiple disorders, including cardiovascular and cerebrovascular diseases, tumors, and infectious diseases (2-6). In the baseline characteristics, $45 \%$ patients suffered different comorbidities. These disorders should be mentioned or adjusted before statistical analysis, such as diabetes mellitus, anemia, cardiovascular diseases, etc.

Secondly, operation and other approaches might influence RDW levels. As hepatic dysfunction and digestive diseases both affected RDW levels $(7,8)$, the surgical methods and range of major hepatic resection and colorectal resection might markedly contribute to the variation of RDW levels. Hemorrhage is also an important confounding factor of RDW levels (2). The blood loss in operation of baseline characteristics changed from 100 to $400 \mathrm{~mL}$. Influence of blood loss or transfusion should be considered. Moreover, $11.1 \%$ patients received concomitant RFA treatment. These factors might affect the changes of RDW levels.

Thirdly, drugs-relative complication should also be taking account or adjusted, especially the myelosuppression response resulted from neoadjuvant chemotherapy or postoperative chemotherapy (9). As an angiogenesis inhibitor, bevacizumab was generally used in CRLM patients in this study. Previous report has proved that bevacizumab raised the risk of bleeding with a relative risk of 2.48 (95\% CI: 1.93-3.18) as comparing to the controls (10). Its drug-relative complications might also change RDW levels, such as hemorrhage or thrombus. Details of these abnormalities were beneficial for readers to further comprehend the clinical value of RDW. 
Summarily, we deemed that the prognostic value of RDW for survival and postoperative complications in CRLM after resection remained arguable. Perhaps, a prospective large-scale research might help to demonstrated the clinical value of RDW in CRLM patients.

\section{Acknowledgments}

Funding: None.

\section{Footnote}

Provenance and Peer Review: This article was a standard submission to the journal. The article did not undergo external peer review.

Conflicts of Interest: Both authors have completed the ICMJE uniform disclosure form (available at https://apm. amegroups.com/article/view/10.21037/apm-21-3369/coif). The authors have no conflicts of interest to declare.

Ethical Statement: The authors are accountable for all aspects of the work in ensuring that questions related to the accuracy or integrity of any part of the work are appropriately investigated and resolved.

Open Access Statement: This is an Open Access article distributed in accordance with the Creative Commons Attribution-NonCommercial-NoDerivs 4.0 International License (CC BY-NC-ND 4.0), which permits the noncommercial replication and distribution of the article with the strict proviso that no changes or edits are made and the original work is properly cited (including links to both the formal publication through the relevant DOI and the license). See: https://creativecommons.org/licenses/by-nc-nd/4.0/.

\section{References}

1. Chen Q, Mao R, Zhao J, et al. Nomograms incorporating preoperative RDW level for the prediction of

Cite this article as: Tan H, Zeng D. Red cell volume distribution width level predicted postoperative complications and survival in colorectal liver metastases after resection. Ann Palliat Med 2022;11(1):410-411. doi: 10.21037/apm-21-3369 postoperative complications and survival in colorectal liver metastases after resection. Ann Palliat Med 2021;10:4143-58.

2. Salvagno GL, Sanchis-Gomar F, Picanza A, et al. Red blood cell distribution width: A simple parameter with multiple clinical applications. Crit Rev Clin Lab Sci 2015;52:86-105.

3. Chen L, Lu XY, Zhu CQ. Prognostic value of albuminred cell distribution width score in patients with severe community-acquired pneumonia. Ann Palliat Med 2020;9:759-65.

4. Xanthopoulos A, Giamouzis G, Melidonis A, et al. Red blood cell distribution width as a prognostic marker in patients with heart failure and diabetes mellitus. Cardiovasc Diabetol 2017;16:81.

5. Kim CH, Park JT, Kim EJ, et al. An increase in red blood cell distribution width from baseline predicts mortality in patients with severe sepsis or septic shock. Crit Care 2013;17:R282.

6. Ai L, Mu S, Hu Y. Prognostic role of RDW in hematological malignancies: a systematic review and metaanalysis. Cancer Cell Int 2018;18:61.

7. Jing JS, Fu XL, Zhao W, et al. Red Cell Distribution Width as a Prognostic Factor in Patients with Hepatocellular Carcinoma. Clin Lab 2020;66:10.7754/ Clin.Lab.2019.191027.

8. Li T, Huang A, Zhang M, et al. Increased Red Blood Cell Volume Distribution Width: Important Clinical Implications in Predicting Gastric Diseases. Clin Lab 2017;63:1199-206.

9. Salem ME, Yin J, Weinberg BA, et al. Clinicopathological differences and survival outcomes with first-line therapy in patients with left-sided colon cancer and rectal cancer: Pooled analysis of 2879 patients from AGITG (MAX), COIN, FOCUS2, OPUS, CRYSTAL and COIN-B trials in the ARCAD database. Eur J Cancer 2018;103:205-13.

10. Hapani S, Sher A, Chu D, et al. Increased risk of serious hemorrhage with bevacizumab in cancer patients: a metaanalysis. Oncology 2010;79:27-38. 